\title{
Evaluation by nanoindentation of technological products manufactured by pulse injection molding process
}

\author{
Margarita Natova $^{1, *}$, Ivan Ivanov ${ }^{2}$, Sabina Cherneva ${ }^{1}$, Maria Datcheva ${ }^{1}$, and Roumen \\ Iankov $^{1}$ \\ ${ }^{1}$ Institute of Mechanics of BAS, Acad. G. Bochev St., B1. 4, 1113 Sofia, Bulgaria \\ ${ }^{2}$ Himicheski Produkti Ltd., 7-b, Sokol St., 8600 Yambol, Bulgaria
}

\begin{abstract}
During conventional polymer injection molding, flow- and weld lines can arise at the molded parts caused by disturbed polymer melt flow when it crosses different parts of the equipment. Such processed plastic goods have discrete zones of inhomogeneities of very small dimensions. In order to stabilize the melt flow and to equalize dimensions of such defective products, an approach for pulse injection molding is applied during production of polymer packagings. Testing methods used for evaluation of macromechanical performance of processed polymer products are not readily applicable to estimate the changes in visual surface obtained during pulse injecting. To overcome this testing inconvenience the performance of processed packagings is evaluated by nanoindentation. Using this method, a quantitative assessment of the polymer properties is obtained from different parts of technological products.
\end{abstract}

\section{Introduction}

When using special effect pigments for producing polymer packagings by injection molding flow and weld lines are frequent aesthetic confronts. Over the past years extensive research has been completed to reduce visibility of such lines repeatedly displayed during the process of injection molding. Further investigation reveals that in injection molded parts various orientations of the melt layers can be seen due to the well-known "fountain flow" in the mold cavities. The reason is established to be the fact that near the mold surface part of the polymer chains is oriented almost parallel to the mold surface and below this layer the chains in the body encompass a "fountain" distribution related to the flowing melt. This orientation in the mold equipment makes areas to have trim med gates and to lack brightness that are representative for microcrystalline polymer materials (Fig. 1). Such a different polymer performance results in a greatly reduced concentration of the pigment, which makes further tool design more challenging.

\footnotetext{
*Corresponding author: mnatova@yahoo.com
} 

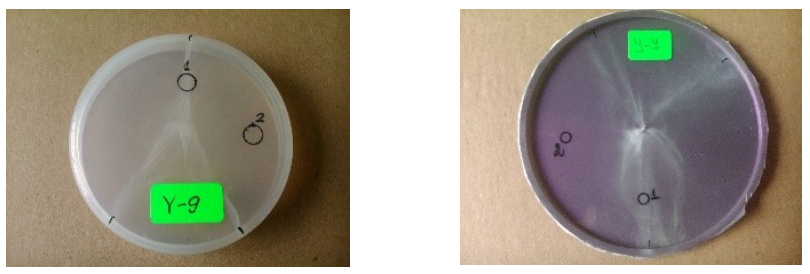

Fig 1. Disposition of visual defects on the injection moulded products

The use of proper molding conditions can help in making produced parts of improved quality. Any changes made to the molding equipment design intended for reducing flow- and weld lines are desired innovation. In producing of injection molded products the uses of sequential, cascade or pulse gating are between the most often used inventions that may reduce visual lines seen and identified with an unaided eye. They are predominantly approved as companies' recommendations and have been included in their prospects and patents. Up to now, no available scientific information is known to explore any new testing methods for numerical estimation of the technological design performance. Transformed technologies for manufacturing of polymeric products involve new melt processing steps that can alter the polymer structure and, through it, the final material performance. In addition, changes in the micro-molecular architecture have a direct impact on the material processability, possibly inducing flow instability [1].

Considering the mechanical behavior of melt boundaries in a micro- and nanocrystalline polymer material there is a large variety of possible relative orientations of the crystals. It is likely that they would be representative micro- and nanometric examples of these visually inhomogeneous boundaries. Thus by examining the properties of those boundaries in a crystalline material, an understanding of their nanomechanical behavior can be obtained [24].

Processed polymer products are inhomogeneous on microscale and appropriately lower load must be used for studying their individual parts. The nanoindentation at low load under specified loading program is used to examine micro-mechanical behavior of polymer products. Reducing the influence of viscoelastic after-effects is achieved by a suitable dwell held for a proper time in between the loading and unloading [5]. The apparent contact stiffness, $S$, is determined from the slope of the upper part of unloading curve.

In order to compare properties of different parts located near to and far from the weld lines of products manufactured with and without the use of a pulsed type of injection the load-displacement curves have been obtained using nanoindentation experiments on Agilent G200 Nanoindenter fitted with a diamond Berkovich type tip. Thus, the nanomechanical response is studied for gaining information for products' indentation hardness and indentation modules. The mechanical response of the specimens can be evaluated comparing their indentation modules and hardness from tests performed on the samples surface.

\section{Experimental}

\subsection{Material and preparation}

Two different brands of polypropylene, Borealis RJ $901 \mathrm{MO}$ and Ineos 450-HP 90, intended for injection moulding were used without further treatment. Manufactured products are transparent and opaque commercial round-shaped containers in three different sizes - $400 \mathrm{ml}$, $180 \mathrm{ml}$ and $100 \mathrm{ml}$, respectively. Containers for pharmaceutical and cosmetic products were made with two types of colorants, giving a pearl shade of the products (light and dark purple). 
Standardized specimens for macro-mechanical testing in a dogbone-shaped form were cut directly from the processed polymer packagings. Thus, the necessity to use methodoriented test standards was fulfilled (according to EN ISO 3167:2014) that defines only specimen geometry and dimensions in addition to test condition requirements [6].

Testing probes for the nanoindentation are cut from the samples without special form and size aiming only to fit the size of the holder in the nanoindenter's tray (a cylindrical punch with a diameter $\phi=31.8 \mathrm{~mm}$ ).

\subsection{Characterization}

Agilent G200 Nanoindenter fitted with a Berkovich three-sided diamond pyramid tip with a rounding of $20 \mathrm{~nm}$ and centreline-to-face angle $65.3^{\circ}$ was used for nanoindentation examinations. The nanoindentation tests were performed under conditions and using a testing program described in details in [7].

Based on the measured load-displacement curves and the methodology described in [8], the indentation modulus and indentation hardness are calculated for each test and the mean values are extracted for comparison.

The hardness is determined from the maximum load and the projection of the contact area $A\left(h_{c}\right)$ :

$$
H_{I T}=P_{\max } / A\left(h_{c}\right)
$$

It is to note that for micro-indentation, the contact area in equation 1 is the surface area of the tip-faces that are in contact with the sample. This explains the difference between the calculated microhardness and indentation hardness. However, the conversion is straightforward and will not be discussed here. It is obvious, therefore, that the trends observed for the indentation hardness hold for the microhardness. by:

The indentation modulus, $E_{I T}$ that may be related to Young's modulus can be calculated

$$
E_{I T}=\left(1-v^{2}\right) /\left[\frac{2 \beta \sqrt{A\left(h_{c}\right)}}{S \sqrt{\pi}}-\left(1-v_{i}^{2}\right) / E_{i}\right]
$$

where $\beta$ is a correction factor, whose value for Berkovich indenter is $\beta=1.03$,

$v$ is the Poisson's ratio of the tested material ( $v=0.42$ in our case),

$E_{i}$ and $v_{i}$ are the indenter's elastic parameters and

$S$ is the elastic contact stiffness defined as the slope of the upper $(50 \%)$ portion of the unloading part of the load-displacement curve [9].

\section{Results and discussion}

In order to improve polymer processing a new pulse melt injecting has been applied. A device engagement was designed and plugged in the production equipment for polymer packagings fabrication (Fig. 2).

Conventional mechanical tests used for evaluating the mechanical properties are not readily applicable to produced polymer goods. To overcome this testing deficiency the mechanical characteristics at the visual surface were assessed from nanoindenter loaddisplacement curves. Indentation hardness, $H_{I T}$, and indentation modulus, $E_{I T}$, have been compared with macromechanically obtained characteristics of the material itself by applying 
tensile load to samples from the same processed packagings as those subjected to nanoindentation testing.

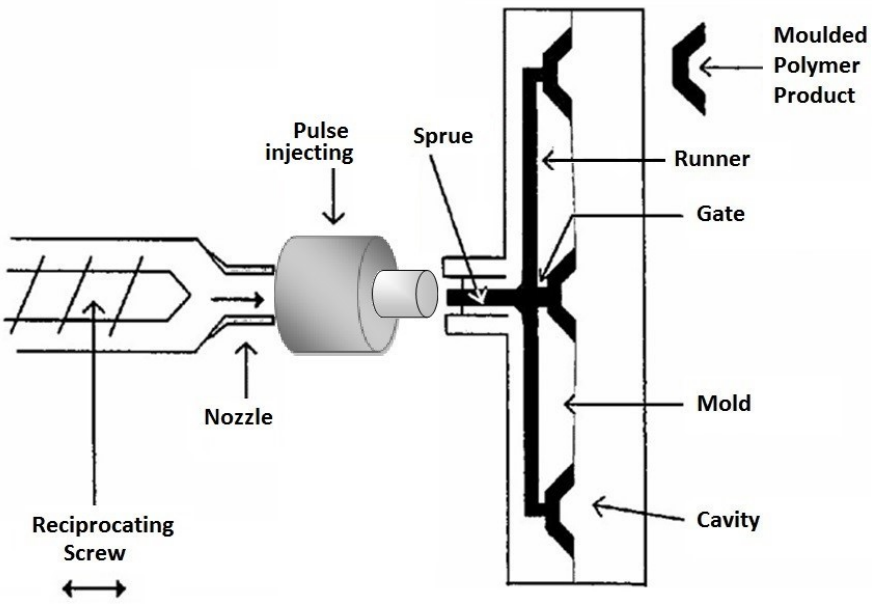

Fig. 2. New device plugged in for pulse injection molding

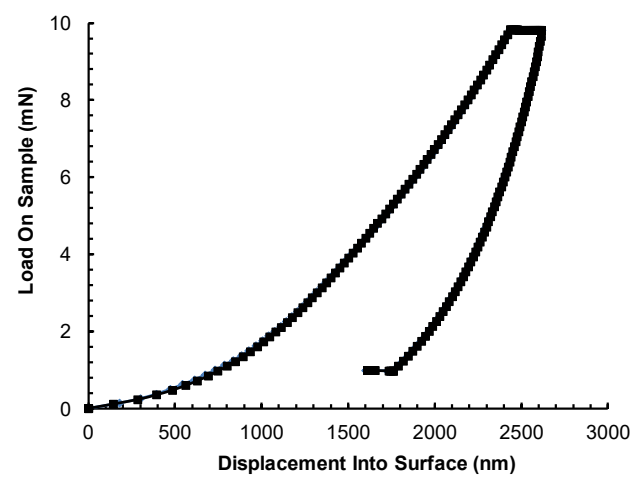

(a)

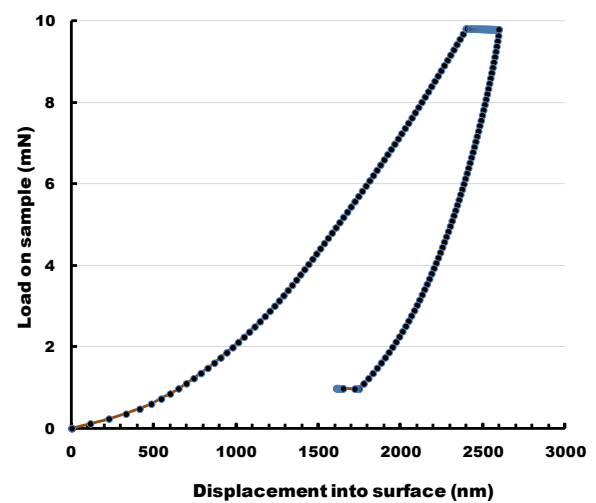

(b)

Fig. 3. Load-displacement curves for Borealis samples obtained far from the weldline without (a) and with (b) pulse injection

To obtain the onset of plasticity with the present loading procedure the study is started by performing nanoindentation at a reasonably small load. Before the onset of plasticity, the load-displacement response is expected to be essentially linear with the slope determined by the elastic properties of the polymer. The unloading part of the measured load-displacement curve is supposed to represent pure elastic material response. The further goal of this research is by microscopical examining of various parts of wall structures - near to and far from the gating system of the equipment and consequently from the weld lines, to provide evidence that yield strength is determined by the structure obtained during processing [9].

Figures $3 \div \mathbf{6}$ show load versus displacement data and images of four representative indentation imprints on sample surfaces manufactured without and with pulse injecting (maximum indention depth is up to $3 \mu \mathrm{m}$ ) (load, $P$, in $m N v s$. penetration depth, $h$, in $\mathrm{nm}$ ). The magnification for the imprint images is 250 times. 
What one in fact measures are the local material properties on the surface area of the polymer samples, and then from the obtained results the polymer bulk mechanical behavior can be inferred.

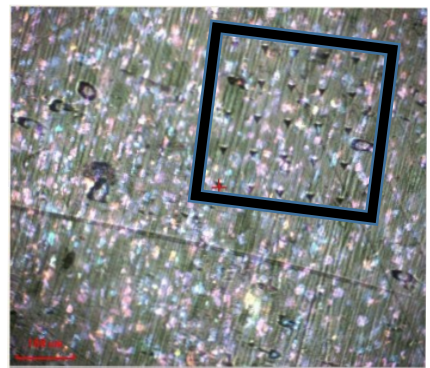

(a)

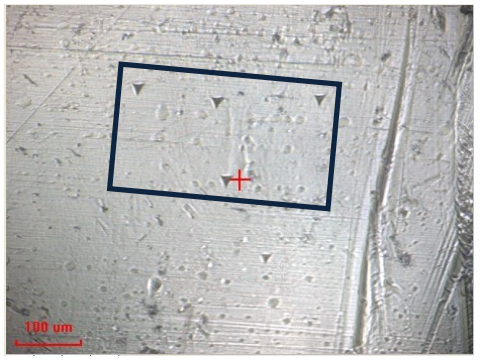

(b)

Fig. 4. Images for Borealis samples obtained far from the weldline without (a) and with (b) pulse injection

From the data in Table 1 it can be concluded that there is a slight reduction of the mechanical properties for the sample located near the weldline due to the manufacturing instability. However, the results show minor inhomogeneity along the $1200 \times 1200$ area that is more pronounced for the sample near to the weldline. Fig. 7 shows as well the variation of mechanical properties for samples with and without pulse injection located near to and far from the weldline along an indentation testing line of $3 \mathrm{~mm}$ length.

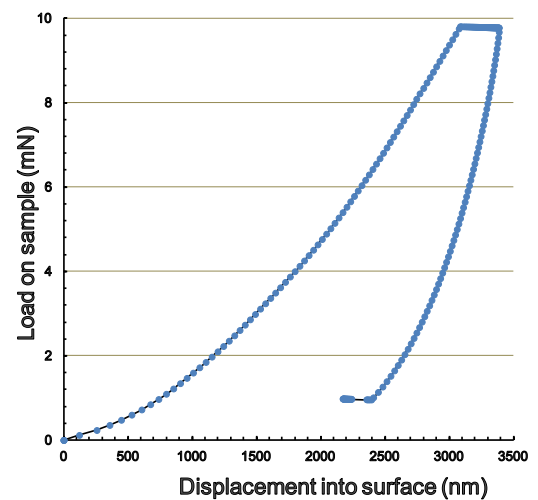

(a)

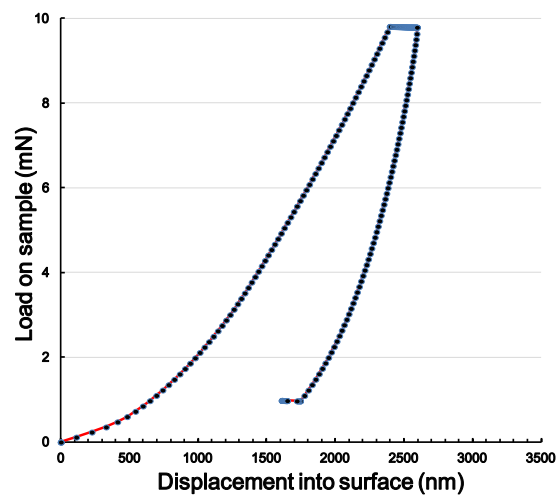

(b)

Fig. 5. Load-displacement curves for Ineos samples obtained near to the weldline without (a) and with (b) pulse injection

An example of the results obtained from macroscopic tensile tests performed without pulse injecting is shown in Fig. 7a. Normal stress-strain behavior is observed for both the samples - near to and far from the weldlines. After passing a maximum tensile stress the stress-strain curves show a commonly occurring decrease, reaching a final failure. Fig. $7 \mathbf{b}$ is an illustration of similar results obtained using pulse injection molding of products.

The difference in absolute values is assumed to be caused by a processing effect governing strengthening mechanism and inducing an amorphization: the higher the inhomogeneity (near to the weldline), the weaker the level of the yield stress. The effective stiffness of products with pulse injecting (Young's modulus $\times$ sample thickness), $S_{\text {eff }}$, of the 
polymer located far from the weldline exceeds the values for samples near to the weldline on average by $8-10 \%$ (the right column of Table 1 ).

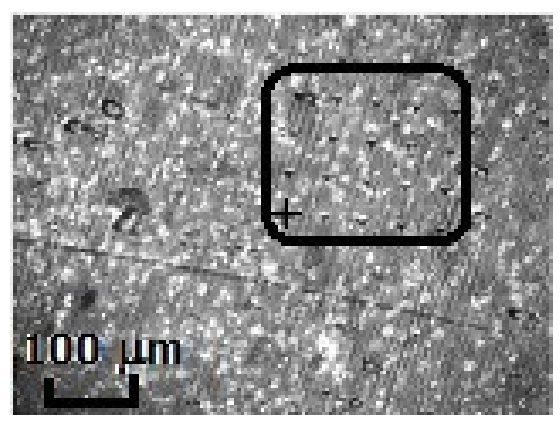

$\mathbf{a}$

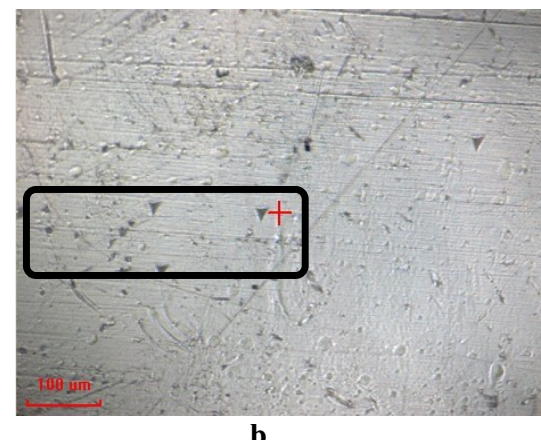

b

Fig. 6. Images for Ineos samples obtained near to the weldline without (a) and with (b) pulse injection

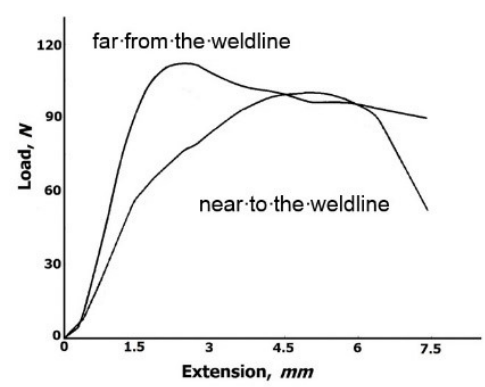

a

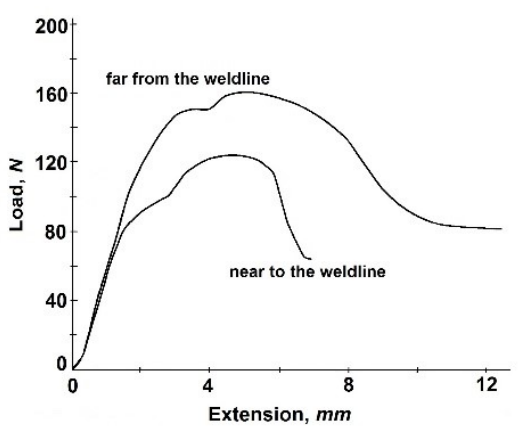

b

Fig. 7. The tensile fracture of samples located near to and far from the weldlines prepared without (a) and with (b) pulse injecting

It is well-established fact that PP is a semicrystalline polymer, and as such it could be meant as a two-phase system. In the simplest case the intrinsic microhardness of the amorphous phase is considerably low than that of the crystalline one, and is approaching zero. Consequently, the microhardness is due to plastic deformation taking place only in the crystalline regions [10]. The increasing transition to an amorphous nature in examined by us PP products is proved by X-ray diffraction experiments (not presented here [11]), and is caused by the pulse type injection molding. It leads to a decrease in microhardness. Since microhardness is related to the packing of the chains in the crystals, polymorphic polymer changes may be expected to influence the strength of the intermolecular forces and, hence, the microhardness.

Specific microhardness measurements were carried out on samples prepared by the temperature-gradient method by the authors Fujiwara, Y. et al. $[12,13]$. Their investigations allow separating of the $\alpha$ (monoclinic) and $\beta$ (hexagonal) phases within the single PP sample. The authors of [14] showed that microhardness decreases when passing from $\alpha$ to the $\beta$ phase, and is partially connected with a crystallinity decrease. Obviously, this is as well the main reason for the microhardness reducing in our experiments carried out using pulse injection molding.

The calculated indentation hardness and modules at the local area of some specific samples are given in Table 1. 
Table 1. Calculated indentation hardness and modules compared to the macromechanical properties for Ineos and Borealis samples with and without pulse injection

\begin{tabular}{|c|c|c|c|c|c|c|c|}
\hline Product & isure & $\begin{array}{l}E_{I T} \\
\text { (MPa) }\end{array}$ & $\begin{array}{l}\text { St. } \\
\text { dev. } \\
\text { (MPa) }\end{array}$ & $\begin{array}{l}H_{I T} \\
\text { (MPa) }\end{array}$ & $\begin{array}{l}\text { St. dev. } \\
\text { (MPa) }\end{array}$ & $\begin{array}{l}\text { Tensile } \\
\text { modules, } \\
E_{\text {tens }} \\
\text { (MPa) }\end{array}$ & $\begin{array}{l}\text { Effective } \\
\text { stiffness, } \\
S_{\text {TensEff }} \\
(\mathrm{MPa} \\
\text { mm) }\end{array}$ \\
\hline Ineos 450- & Wall & 1129 & 58 & 55 & 4 & 404 & 426 \\
\hline HP90 & Bottom & 1290 & 34 & 72 & 1 & 413 & 392 \\
\hline Ineos 450- & Wall & 933 & 11 & 47 & 1 & 347 & 356 \\
\hline $\begin{array}{l}\text { with pulse } \\
\text { injection }\end{array}$ & Bottom & 1392 & 40 & 77 & 3 & 431 & 426 \\
\hline Borealis RJ & Wall & 1003 & 43 & 54 & 3 & 328 & 295 \\
\hline 901 МО & Bottom & 1147 & 13 & 55 & 1 & 385 & 366 \\
\hline Borealis RJ & Wall & 1103 & 23 & 60 & 1 & 316 & 278 \\
\hline $\begin{array}{l}\text { with pulse } \\
\text { injection }\end{array}$ & Bottom & 1133 & 31 & 56 & 3 & 380 & 327 \\
\hline
\end{tabular}

The authors of [15] have found an experimental relationship between indentation hardness and modulus and tensile modulus and/or yield stress for injection-molded semicrystalline plastics. According to the classical theory of polymer plasticity the expected indentation hardness should be approximately equal to three times the yield stress. Therefore, we might expect such a relationship with a certain variation of the microhardness/tensile yield $\sim 3$ ratio caused by the proportion of the participating amorphous and crystalline phases. On the Table 1 it can be noted that in our case the elastic modulus measured by nanoindentation technique is 2.7-3.3 times higher than that obtained by tensile tests what is in excellent agreement with the well-known empirical relationship. The difference between these results again reflects the fact that under tension loads full breaking of polymer bonds occurs, whereas in nanoindentation, which applies a sensibly low load, the bonds are only disrupted and not destructed. Thus, the nanometric technique underestimates the mechanical properties.

\section{Conclusions}

The Agilent G200 NanoIndenter was successfully used to determine the indentation modules and indentation hardness of two types of technological polypropylene samples containing or free of manufacturing defects. It has been clearly demonstrated that irregularities in the sample topography can produce little but notable changes in the perceived properties.

The indentation hardness of the products varies depending on the position of the sample examined. The local inhomogeneities that occur as a changing proportion between amorphous and crystalline phases obviously affects the indentation hardness. The incipient plasticity is observed to be not quite different but noticeable among the different parts of the samples.

The inhomogeneous sample surface did not introduce substantial differences into the near-surface region of the sample and did not considerably affect the measurement by the 
Berkovich indenter tip. A reason may be that the used here indenter tip is a very sharp pyramid that may cut the polypropylene rather than to deform it.

Based on the obtained nano- and macro-mechanical results an assumption can be made for the assessment of polymer processing effect occurring after application of the pulse injection moulding. It is proved that enhanced product performance is due to the fact that pulse injecting intensifies the molecular diffusion across the weld lines so as to reduce the polymer crystallinity thus decreasing the weldline weakness without creating any visible marks.

The experimental data can be successfully used for evaluation of dissimilarity in different areas of the polymer product and to estimate their mechanical characteristics, for postproduced sorting and classification before exploitation of polymer packagings.

Authors gratefully acknowledge the financial support of the Bulgarian National Science Fund under Grant No. T02-22/12.12.2014.

\section{References}

1. G. Filippone, S. C. Carroccio, R. Mendichi, L. Gioiella, N. Tz. Dintcheva, C. Gambarotti, Polymer, 72, 134-141 (2015).

2. K. T. Ramesh, Nanomaterials: Mechanics and Mechanisms, Springer Science + Business Media LLC (2009).

3. Materials Characterization: Modern Methods and Applications, Edited by Narayanaswami Ranganathan, Taylor \& Francis Group LLC (2016).

4. W. D. Nix, Metallurgical transactions a-physical metallurgy and materials science, 20, 11, 2217-2247(1989).

5. Nanoindentation in Materials Science, Ed. J. Němeček, InTech, Rijeka, Croatia (2012).

6. W. Oliver, G. Pharr, J. of Mat. Research, 19, 1, 3-20 (2004).

7. M. Natova, Iv. Ivanov, R. Iankov, M. Datcheva, S. Cherneva, 16th Int. Multidisciplinary Scientific Geoconf. SGEM 2016, 28 June - 7 July 2016, Volume Nano, Bio and Green - Technologies for a sustainable future, Albena Co. - Varna, Bulgaria, 111-118 (2016).

8. Polymer Testing, 2nd Edition. Eds. W. Grellmann, S. Seidler, Carl Hanser Verlag, Munich (2013).

9. N. M. Jennett, R. Ghisleni, J. Michler, Appl. Phys. Lett., 95, 12, 123102 (2009).

10. F. J. Baltá Calleja, S. Fakirov, Microhardness of polymers, Cambridge University Press, New York (2000).

11. M. Natova, Iv. Ivanov, V. Georgiev, F. Ublekov, Hr. Penchev, 46th IUPAC World Polymer Congress MACRO 2016, Istanbul, Turkey (2016).

12. Y. Fujiwara, Koll. Zeitsch. und Zeitsch. für Polymere, 226, 2, 135-138 (1968).

13. T. Asano, Y. Fujiwara, Polymer, 19, 1, 99-108 (1978).

14. F. J. Baltá Calleja, J. Martinez-Salazar, T. Asano, Mater. Sci. Lett., 7, 2, 165-166 (1988).

15. J. Bowman, M. Bevis, Colloid Polym. Sci., 255, 10, 954-966 (1977). 